\title{
NUTRIENTES NO SOLO DE DUAS FLORESTAS DA PLANÍCIE LITORÂNEA DA ILHA DO MEL, PARANAGUÁ, PR ${ }^{(1)}$
}

\author{
R. M. BRITEZ ${ }^{(2,5)}$, A. SANTOS FILHO ${ }^{(2)}$ C. B. REISSMANN ${ }^{(2)}$,

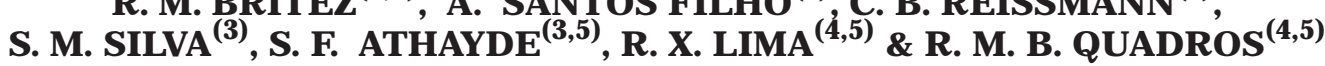

\section{RESUMO}

Estudou-se a ciclagem de nutrientes de duas formações florestais ("floresta baixa", com dossel atingindo $15 \mathrm{~m}$ de altura, e "floresta alta", $25 \mathrm{~m}$ de altura), características dos cordões arenosos da planície litorânea da Il ha do Mel, Paranaguá, Paraná, de 14 de junho de 1991 a 12 de junho de 1993. Nesta primeira parte, foram analisadas as características químicas e físicas dos solos, relacionando-as com o meio físico e com o material de origem. Os solos foram classificados como podzóis, distróficos e álicos, fortemente ácidos, de textura arenosa, estando a profundidade do horizonte B iluvial relacionada com a faixa de oscilação do lençol freático. Nas duas áreas, os solos apresentam fertilidade semel hante, caracterizando-se pela baixa CTC, alto potencial de lixiviação, fazendo com que a matéria orgâni ca seja a principal responsável pela retenção de íons no solo. Ocorrem, também, dois compartimentos distintos de nutrientes, um no horizonte Al e outro no B iluvial. E mbora a fertilidade dos solos seja considerada bastante baixa, a vegetação apresenta-se bem desenvolvida. As diferenças no desenvolvimento entre as duas florestas estudadas podem estar relacionadas com a disponi bilidade de água e de nutrientes do horizonte B. Na floresta alta, tanto o lençol freático como o horizonte B estão mais próximos da superfície, possibilitando que essa formação esteja menos sujeita ao estresse hídrico, além de poder aproveitar, mais facilmente, os nutrientes acumulados no horizonte B.

Termos de indexação: ciclagem de nutrientes, podzol, estoque de nutrientes, floresta tropical.

\section{SUMMARY: SOIL NUTRIENTS IN TWO FOREST TYPES ON THE COASTAL PLAINS OF ILHA DO MEL, PARANAGUÁ, STATE OF PARANÁ, BRAZIL.}

Thenutrient cycling of two types of vegetation, (a "low forest" - 15 m of height, and a "short forest" - $25 \mathrm{~m}$ of height), characteristic of the sandy belts on the Coastal Plains of II ha do Mel

\footnotetext{
(1) Trabalho extraído de tese do primeiro autor, apresentada ao Curso do Pós-Graduação em Agronomia da Universidade Federal do Paraná - UFPR. Financiado pelo CNPq. Recebido para publicação em agosto de 1995 e aprovado em outubro de 1997.

(2) Departamento de Solos do Setor de Ciências Agrárias da UFPR. Caixa Postal 672, CEP 80035-050 Curitiba (PR).

(3) Departamento de Botânica do Setor de Ciências Biológicas da UFPR. CEP 80530-000 Curitiba (PR).

(4) Departamento de Silvicultura e Manejo do Setor de Ciências Agrárias da UFPR. CEP 80035-010 Curitiba (PR).

${ }^{(5)}$ Bolsista da CAPES
} 


\begin{abstract}
was studied, from J une 14th, 1991 to J une 12th, 1993. In this first step the soil's chemi cal and physical characteristics were studied, in relation to the physical environment and the parent material. The soils were classified as allic/ dystrophic podzols, where the B spodic horizon's depth is related to theoscilating watertable Organic matter is the main causefor the retention of ions in thesoil. Thesoils from thetwo areas aresimilar in fertility level, characterized by the Iow CEC, high leaching potential, high acidity, distrophic and al ic Although the soils fertility may beconsidered very low, thevegetation is well developed. The differences betwen theforests types may berelated to thewater and nutrient availability in theB horizon. In the "tall forest", the watertable and the $B$ horizon are closer to the surface, being less subject to the water stress and having more ability to utilize the nutrient availability in this horizon.
\end{abstract}

Index terms: nutrient cycling, nutrient stock, spodosol, tropical forest.

\section{INTRODUÇÃO}

No estudo da ciclagem de nutrientes, a quantificação das reservas minerais e orgânicas esuas transferências entre compartimentos são de extrema importância para entender e comparar os diferentes ecossistemas e suas inter-relações com o meio. No ecossistema florestal, essas reservas acumulam-se na vegetação, nos animais, na serapilheira eno solo. Este último, além de servir como substrato para a vegetação, constitui importante compartimento de onde é retirada a maior parte dos nutrientes necessários à sobrevivência das plantas.

O estoque de nutrientes totais e os disponíveis às plantas nos solos foram quantificados em vários estudos referentes à ciclagem de nutrientes (Tanner, 1977; Golley et al., 1978; Edwards \& Grubb, 1982; Delitti, 1984; Santos, 1989), que objetivaram avaliar a transferência de nutrientes entre compartimentos em ecossistemas florestais.

A intemperização da rocha matriz representa uma fonte de entrada de nutrientes nesses ecossistemas, ditando, também, as principais características químicas efísicas dos solos. Na ll ha do Mel, omaterial originário da planícielitorânea e, conseqüentemente, dos sol os é proveniente da sedimentação das areias reliquiares das plataformas continentais adjacentes (Suguio \& Martin, 1990), tendo os cordões litorâneos sido formados durante a descida do nível do mar, na fase regressiva da última transgressão, há 5.100 anos A.P. (Angulo, 1992).

Segundo EMBRAPA (1984), os solos com B podzol ou "spodic horizon" ocorrem em uma extensão de 855 $\mathrm{Km}^{2}$, no litoral do Estado do Paraná $(0,43 \%$ da área do Éstado). São solos muito pouco estudados, não existindo no levantamento de reconhecimento dos solos do Estado do Paraná (EMBRAPA, 1984) nenhuma descrição de perfil, sendo identificado apenas um podzol hidromórfico, sem distinguir as diversas situações em que esse solo pode ocorrer, de acordo com as diferentes fisionomias da vegetação estabelecida nas planícies arenosas do litoral do Estado. Santos Filho \& Tourinho (1983) classificaram um podzol hidromórfico na faixa litorânea paranaense, indicando um possível transporte de matéria orgânica, ferro eal umínio do horizonteel uvial (E) para os horizontes iluviais (Bh e Bs). Rocha et al. (1987), em estudos realizados sobre as condições edáficas para o desenvol vimento do pal mito no litoral paranaense, dassificaram sol os de origem sedimentar marinha, podzol hidromórfico e areia quartzosa marinha, descrevendo-os química e fisicamente.

Estetrabal hoé parte de um outro em que se estuda a ciclagem de nutrientes em duas formações vegetais, características dos cordões arenosos da planície litorânea da Il ha do Mel. Teve como objetivo avaliar as características químicas, físicas e o estoque de nutrientes do solo, procurando relacioná-los com as diferentes tipol ogias florestais.

\section{MATE RIAL E MÉTODOS}

A Il ha do Mel situa-se na entrada da Baía de Paranaguá, litoral centro do Estado, fazendo parte do município de Paranaguá, com coordenadas: $25^{\circ} 30^{\prime} \mathrm{S}$ e $48^{\circ} 20^{\prime} \mathrm{W}$, possui perímetro de, aproximadamente, $35 \mathrm{Km}$ eárea de 2.760 ha. Caracteriza-se, em termos de geomorfol ogia, por uma extensa planície costeira, que representa $90 \%$ da sua área total, sendo o restante formado por morros oriundos do afloramento do compl exo cristalino, onde o mais alto atinge $150 \mathrm{~m}$.

A planície costeira tem uma altura predominante entre 2,5 e 3 m sobre o nível da maré alta, atingindo 4-5 $\mathrm{m}$ em alguns locais. Observam-se alinhamentos bem definidos por mudanças de vegetação (cordões litorâneos), que correspondem a feições topográficas lineares, com espaçamento entre 10 e $20 \mathrm{~m}$. Nas partes mais baixas do terreno, ocorrem pequenos córregos ou áreas freqüentemente alagadas, cuja vegetação é mais alta que a circundante (Angulo, 1992).

$\mathrm{A}$ área de estudo encontra-se na planície costeira dentro da Estação E cológica da I lha do Mel, na região denominada praia das Conchas, a uma distância de, aproximadamente, 100 metros do mar.

As duas formações vegetais estudadas caracterizam-se por ocorrerem próximas uma da outra e serão denominadas de "floresta baixa" e "floresta alta", correspondendo a formações com o estrato arbóreo superior, com alturas entre 8-15 e 15-25 m, respectivamente (Figura1). Enquanto a primeira surge nas partes mais el evadas dos cordões litorâneos, em local mais seco, a segunda aparece nas depressões, onde, freqüentemente, há o afloramento do lençol freático. 
No estudo dos solos, utilizaram-setrês trincheiras: duas na floresta baixa e uma na floresta alta. Optouse por fazer duas amostragens na floresta baixa, em função de pequenas oscilações no terreno, - um perfil em área mais el evada e outro em área mais baixa visto que na floresta alta o terreno era mais homogêneo (Figura 1).

$\mathrm{Na}$ descrição morfológica dos perfis, adotou-se o roteiro recomendado por Lemos \& Santos (1984).

As amostras de solo foram secas, destorroadas e peneiradas, obtendo-se a fração $<2 \mathrm{~mm}$, a qual foi submetida às seguintes análises, de acordo com as recomendações da EMBRAPA (1979): pH, em sol ução $0,01 \mathrm{~mol} \mathrm{~L}^{-1}$ de cloreto de cálcio; $\mathrm{Ca}^{2+}, \mathrm{Mg}^{2+}$ e $\mathrm{Al}^{3+}$ extraíveis com cloreto de potássio $1 \mathrm{~mol} \mathrm{~L}^{-1} ; \mathrm{K}^{+}$ extraível com ácido clorídrico 0,05 $\mathrm{mol} \mathrm{L}^{-1}$; acidez extraível $\left(\mathrm{H}^{+}+\mathrm{Al}^{3+}\right)$ com acetato de cálcio $1 \mathrm{~mol} \mathrm{~L}^{-1} \mathrm{a}$ pH 7; P extraível pelo extrator Mehlich-1, densidade aparente pelo método de anéis volumétricos, e granulometria, pelo método Vettori \& Pierantoni (1968).

Dos resultados obtidos, calcularam-se os seguintes valores: soma de bases (S), capacidade de troca catiônica total $(T)$, saturação por bases $(V)$, saturação por alumínio (m).

Os sol os foram classificados segundo as normas da EMBRAPA (1988).
Foram determinados os teores totais de $\mathrm{N}, \mathrm{P}, \mathrm{K}$, $\mathrm{Ca}, \mathrm{Mg}, \mathrm{Fe}, \mathrm{Mn}, \mathrm{Cu}, \mathrm{Zn}$ eAl no solo, segundo o método descrito por Hildebrand (1977), por meio da digestão, com ácido fluorídrico e ácido perclórico.

As leituras de $\mathrm{K}, \mathrm{Ca}, \mathrm{Mg}, \mathrm{Fe}, \mathrm{Mn}, \mathrm{Cu}, \mathrm{Zn}$ eAl foram realizadas em espectrofotômetro de absor ção atômica 2380 Perkin-E Imer, eas de P, pelo método col orimétrico em espectrofotômetroUVNIS 554 Perkim - Elmer. O $\mathrm{N}$ foi determinado pelo método Kjeldahl.

Para estimar as quantidades de nutrientes totais e trocáveis, calculou-se a massa do solo por meio da fórmula proposta por Reichardt (1987).

\section{RESULTADOS E DISCUSSÃO}

A descrição geral dos perfis e a classificação dos sol os encontram-se no quadro 1.

A floresta alta apresentou o horizonte A1 mais desenvol vido em relação ao da floresta baixa, devido ao maior aporte de matéria orgânica. A floresta alta deposita $7,7 \mathrm{t} \mathrm{ha}^{-1} \mathrm{ano}^{-1}$ de serapilheira, e a floresta baixa 5,2 t ha-1 ano-1 (Britez, 1994).

A classetextural dos solos éareia, correspondendo à textura arenosa (EMBRAPA, 1988), com pouca quantidade de argila, eval ores mais el evados de silte

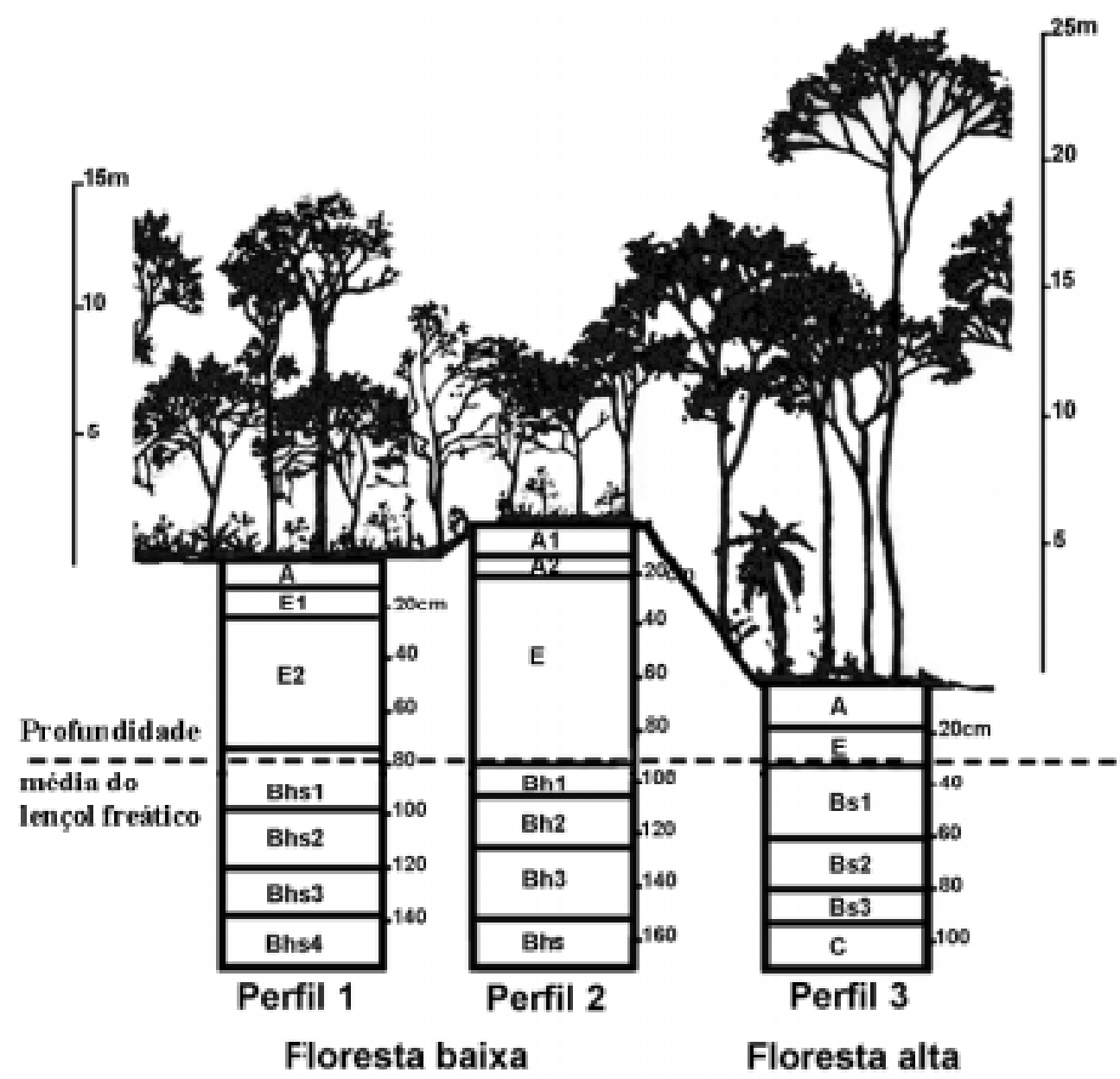

Figura 1. Desenho esquemático da localização dos perfis nas áreas amostradas. 
Quadro 1. Descrição geral dos perfis de solo

\section{Perfil 1 - Floresta baixa}

Classificação - Podzol distrófico e álico A fraco textura arenosa fase floresta não hidrófila de restinga com relevo plano.

Localização - Il ha do Mel, Município de Paranaguá, PR.

Litologia e formação geológica - Planície arenosa quaternária.

Material de origem - Sedimentos marinhos depositados no período Quaternário.

Relevo - Plano.

Drenagem - Excessivamente drenado.

Vegetação primária - Floresta não hidrófila de restinga.

Uso atual - Área de Preservação Permanente.

Descrição morfológica

A - 0-12 cm, cinza-escuro (5 YR 4/1, úmido); areia; grãos simples; sol to, não plástico e não pegajoso.

E1 - 12-25 cm, cinza (5 YR 6/1, úmido); areia; grãos simples; solto, não plástico e não pegajoso.

E2 - 25-74 cm, cinza claro (5 YR 7/1, úmido); areia; grãos simples; solto, não plástico e não pegajoso.

Bhs1 - 74-98 cm, bruno (7,5 YR 5/4, úmido); areia; grãos simples; solto, não plástico e não pegajoso.

Bhs2 - 98-120 cm, bruno-avermel hado-escuro (5 YR 3/4, úmido); areia; fraca pequena granular; solto, ligeiramente plástico e ligeiramente pegajoso.

Bhs3 - 120 -138 cm, bruno muito escuro (10 YR 2/2, úmido); areia; fraca pequena granular; sol to, ligeiramente plástico e ligeiramente pegajoso.

Bhs4 - 138 - 161+cm, bruno-escuro (7,5 YR 3/4, úmido); areia; fraca pequena granular; solto, ligeiramente plástico e ligei ramente pegajoso.

\section{Perfil 2 - Floresta baixa}

Classificação - Podzol distrófico e álico A moderado textura arenosa fase floresta não hidrófila de restinga com relevo plano.

Localização - Il ha do Mel, Município de Paranaguá, PR.

Litologia e formação geológica - Planície arenosa quaternária.

Material de origem - Sedimentos marinhos depositados no período Quaternário.

Relevo - Plano.

Drenagem - Excessivamente drenado

Vegetação primária - Floresta não hidrófila de restinga.

Uso atual - Área de Preservação Permanente.

Descrição morfológica

A1 - 0-13 cm, cinza (10 YR 5/1, úmi do); areia; grãos simples; solto, não plástico e não pegajoso.

A2 - 13-20 cm, bruno (7,5 YR 5/2, úmido); areia; grãos simples; solto, não plástico e não pegajoso.

E - 20-93 cm, cinzento-rosado (7,5 YR 7/2, úmido); areia; grãos simples; sol to, não plástico e não pegajoso.

Bh1 - 93-106 cm, bruno (7,5 YR 5/4, úmido); areia; grãos simples; solto, não plástico e não pegajoso.

Bh2 - 106-125 cm, bruno muito escuro (10 YR 2/2, úmido); areia; grãos simples; sol to, ligeiramente plástico e ligei ramente pegajoso.

Bh3 - 125 -153 cm, preto ( 10 YR 2/1, úmido); areia; fraca pequena granular; sol to, ligeiramente plástico e ligei ramente pegajoso.

Bhs - 153 - 169+cm, bruno muito escuro (10 YR 2/2, úmido); areia; fraca pequena granular; sol to, ligeiramente plástico e ligeiramente pegajoso.

\section{Perfil 3 - Floresta alta}

Classificação - Podzol distrófico A moderado textura arenosa fase flor esta hidrófila de restinga com rel evo plano.

Localização - II ha do Mel, Município de Paranaguá, PR.

Litologia e formação geológica - Planície arenosa quaternária.

Material de origem - Sedimentos marinhos depositados no período Quaternário.

Relevo - Plano.

Drenagem - Moderadamente drenado.

Vegetação primária - Floresta hidrófila de restinga.

Uso atual - Área de Preservação Permanente.

Descrição morfológica

A - 0-18 cm, cinza muito escuro (5 YR 3/1, úmido); areia; grãos simples; solto, não plástico e não pegajoso.

E - 18-32 cm, bruno-acinzentado (10 YR 5/2, úmido); areia; grãos simples; solto, não plástico e não pegajoso.

Bs1 - 32-61 cm, bruno-amarelado (10 YR 5/4, úmido); areia; grãos simples; solto, não plástico e não pegajoso.

Bs2 - 61-80 cm, bruno-amarelado-escuro (10 YR 4/4, úmido); areia; fraca pequena granular sol to, ligeiramente plástico e ligeiramente pegajoso.

Bs3 - 80-93 cm, bruno-acinzentado muito escuro (10 YR 3/2, úmido); areia; fraca pequena granular; solto, ligei ramente plástico e ligei ramente pegajoso.

C - 93 - 118+ cm, bruno-amarelado-escuro (10 YR 4/4, úmido); areia; fraca pequena granular; sol to, ligeiramente plástico e ligeiramente pegajoso. 
no horizonte A1 (Quadro 2). Os perfis estudados não apresentaram diferenças quanto à composição granulométrica, predominando a areia fina (diâmetro entre 0,02 e 0,2 mm). Angulo (1992) encontrou média de diâmetros dos sedimentos arenosos de origem marinha no Estado do Paraná de 0,156 mm.

A textura arenosa confere aos solos da planície litorânea baixa retenção de nutrientes e de água. As chuvas, com, aproximadamente, $2.000 \mathrm{~mm}$ anuais (Silva, 1990), tendem a lixiviar a mai or parte dos nutrientes, enquanto, nos interval os entre os eventos, os sol os permanecem com baixa umidade.

O horizonte $B$ dos perfis 1 e 2 da floresta baixa esta à profundidades de $74 \mathrm{e} 93 \mathrm{~cm}$, respectivamente, enquanto o B da floresta alta está a $32 \mathrm{~cm}$ de profundidade. Essas diferenças na profundidade do $\mathrm{B}$ entre as áreas podem estar relacionadas com a oscilação do lençol freático. Britez (1994), analisando medidas feitas em um período de dois anos, verificou que a profundidade média do lençol foi de $94 \mathrm{~cm}$ na floresta baixa e de $40 \mathrm{~cm}$ na floresta alta (Figura 1), portanto com médias de oscilação próximas às alturas de ocorrência do horizonte B. Supõe-seque o material translocado para esse horizonte, por ser solúvel, diluise na água do lençol freático, precipitando-se, gradativamente, conforme sua oscilação. Isso se baseia em resultados analíticos da água do lençol freático realizados mensalmente (Britez, 1994), para a qual as concentrações médias anuais (em $\mathrm{mg} \mathrm{kg}^{-1}$ ) foram, para a floresta baixa e alta, respectivamente, as seguintes: P, 0,039 e 0,058; K, 1,75 e 1,37; Ca, 6,55 e
8,26; $\mathrm{Mg}, 2,5$ e 2,9; Fe, 0,63 e 0,75; Zn, 0,25 e 0,10; Al, 1,4 e 1,3; Si, 2,7 e 4,4 .

O horizonte $B$ aparentementenão representa uma barreira para a movimentação da água do lençol freático, visto que não difere dos demais horizontes em consistência (solta - Quadro 1), apresentando apenas uma ligeira plasticidade e pegajosidade.

Os val ores de $\mathrm{pH}$ em $\mathrm{CaCl}_{2}$ são considerados muito baixos, variando de 3,4 a 4,2, indicando um solo fortementeácido (Quadro 3). No solo da floresta alta, houve um aumento do $\mathrm{pH}$ nos horizontes iluviais e uma dimi nui ção na quanti dade de carbono. Na floresta baixa, o pH manteve-se inalterado no horizonte $B$, havendo um aumento na quantidade de carbono em relação ao horizonte $\mathrm{E}$.

A forte acidez do solo propicia o aparecimento de alumínio trocável, o que é comprovado pela alta porcentagem de saturação em alumínio, próxima a 50\% em todos os horizontes da floresta alta emai or que $60 \%$ nos suborizontes iluviais mais profundos da floresta baixa. Em contrapartida, os valores deV são, na maior parte dos três perfis estudados, menores que $20 \%$, indicando que apenas pequenas quantidades de bases trocáveis ocupam os sítios de carga negativa, os quais, em sua maior parte, estão saturados pelo Al.

Acredita-se quea matéria orgânica seja a principal responsável pela retenção de cátions nos solos estudados, onde, nos horizontes superficiais existe uma quantidade mai or denutrientes disponíveis. Hay \& Lacerda (1980) e Hay et al. (1981) obtiveram correlações altas entre matéria orgânica e capacidade

Quadro 2. Características granulométricas dos solos e profundidade dos horizontes dos três perfis do Podzol

\begin{tabular}{|c|c|c|c|c|c|c|c|}
\hline \multirow{2}{*}{ Horizonte } & \multicolumn{6}{|c|}{ Granulometria da terra fina } & \multirow{2}{*}{$\begin{array}{c}\text { Densidade } \\
\text { do solo }\end{array}$} \\
\hline & Profundidade & Areia grossa & Areia fina & Areia & Silte & Argila & \\
\hline & $\mathrm{cm}$ & $\longrightarrow$ & 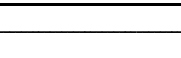 & $-\mathrm{g} \mathrm{kg}^{-1}$ & & & $\mathrm{~kg} \mathrm{md}^{-3}$ \\
\hline \multicolumn{8}{|c|}{ Perfil 1} \\
\hline $\mathrm{A}$ & 0-12 & 20 & 720 & 740 & 200 & 60 & 0,69 \\
\hline E 1 & $12-25$ & 20 & 860 & 880 & 100 & 20 & 1,14 \\
\hline E 2 & $25-74$ & 20 & 960 & 980 & 00 & 20 & 1,27 \\
\hline Bhs1 & 74-98 & 20 & 940 & 960 & 20 & 20 & 1,32 \\
\hline Bhs2 & 98-120 & 00 & 980 & 980 & 00 & 20 & 1,48 \\
\hline Bhs3 & 120-138 & 20 & 960 & 980 & 00 & 20 & 1,42 \\
\hline Bhs4 & $138-161+$ & 00 & 980 & 980 & 00 & 20 & 1,36 \\
\hline \multicolumn{8}{|c|}{ Perfil 2} \\
\hline A 1 & 0-13 & 00 & 800 & 800 & 160 & 40 & 0,92 \\
\hline A2 & $13-20$ & 20 & 940 & 940 & 00 & 40 & 0,97 \\
\hline $\mathrm{E}$ & $20-93$ & 00 & 980 & 980 & 00 & 20 & 1,36 \\
\hline Bh1 & 93-106 & 00 & 980 & 980 & 00 & 20 & 1,44 \\
\hline $\mathrm{Bh} 2$ & $106-125$ & 20 & 940 & 960 & 00 & 40 & 1,47 \\
\hline Bh3 & $125-153$ & 00 & 980 & 980 & 00 & 20 & 1,48 \\
\hline Bhs & $153-169+$ & 40 & 940 & 980 & 00 & 20 & 1,43 \\
\hline \multicolumn{8}{|c|}{ Perfil 3} \\
\hline$A$ & 0-18 & 20 & 780 & 800 & 160 & 40 & 0,79 \\
\hline $\mathrm{E}$ & $18-32$ & 20 & 940 & 960 & 00 & 40 & 1,44 \\
\hline Bsl & $32-61$ & 20 & 920 & 940 & 20 & 40 & 1,42 \\
\hline Bs2 & $61-80$ & 20 & 920 & 940 & 20 & 40 & 1,45 \\
\hline Bs3 & $80-93$ & 20 & 960 & 980 & 00 & 20 & 1,42 \\
\hline $\mathrm{C}$ & $93-118+$ & 20 & 940 & 960 & 20 & 20 & 1,4 \\
\hline
\end{tabular}


Quadro 3. Características químicas dos solos

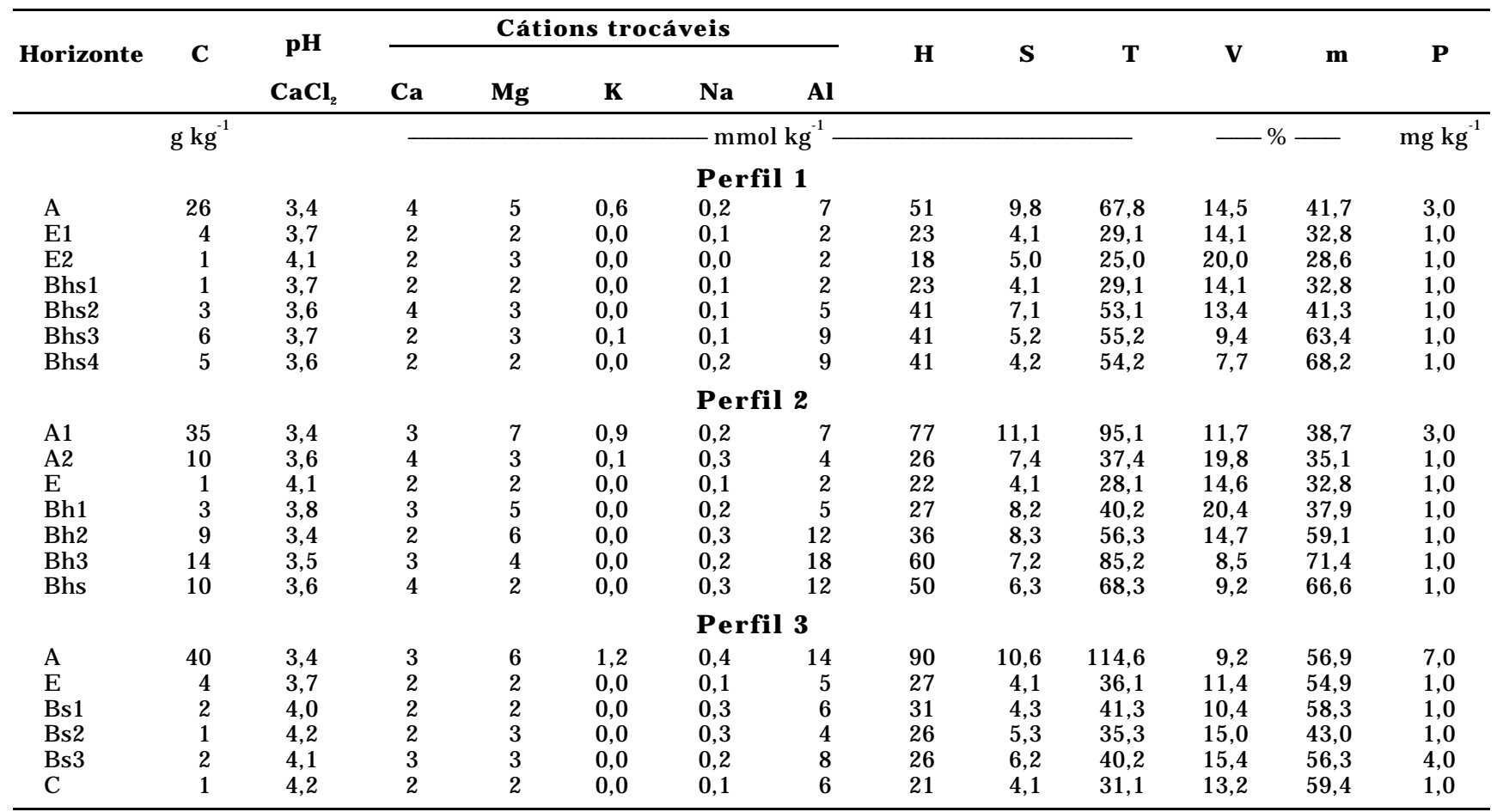

de troca catiônica em sol os de restinga. Silva (1990), além da correlação da matéria orgânica e capacidade detroca catiônica nos solos da restinga da I lha do Mel, obteve correlações significativas entre matéria orgânica e P, K, Mg e Ca.

No podzol das áreas estudadas, o carbono, os elementos trocáveis, a soma de bases, a capacidade de troca catiônica e o fósforo apresentaram val ores mais elevados no horizonte $A 1$, em decorrência da deposição de serapilheira; o horizonte $\mathrm{E}$ apresentou os menores valores, enquanto, no horizonte B iluvial, os val ores el evaram-se, novamente, em razão do acúmulo de íons, proveniente da transl ocação do horizonte $\mathrm{E}$.

O quadro 4 apresenta os resultados dos teores totais nos três perfis de solos estudados. Estes indicam as concentrações totais dos elementos no sol o, provenientes dos elementos contidos na matéria orgânica depositada pela vegetação, da precipitação atmosférica e dos minerais que compõem as areias da planície litorânea.

A quantidade de elementos totais e trocáveis (Quadros 5 e 6) nos horizontes dos perfis estudados, representa o estoque de nutrientes no sol o.

Angulo et al. (1994), em estudos sedimentológicos na ilha do Mel, analisaram a composi ção dos minerais pesados translúcidos em vários pontos da ilha, encontrando, em média, as seguintes percentagens; turmalina $(37 \%)$, zircon $(20 \%)$, pistacita (12\%), estaurolita (10\%), kyanita, sillimanita e hornblenda (5\%). Angulo (comun. pessoal), anal isando os minerais opacos dequatro amostras dos perfis desol os estudados, encontrou, em sua composição, quartzo, feldspato, magnetita, ilmenita, dentre outros não identificados. A composição desses mi nerais pode ser vista no quadro 7.
A maior parte do $\mathrm{N}$ total contido no solo está associado à matéria orgânica, justificando suas concentrações mai ores no horizonteA 1 , onde ocorrea deposição de material orgânico proveniente da floresta, muito pouca quantidade desse elemento é translocada ao horizonte iluvial. A floresta alta apresenta uma concentração de $\mathrm{N}$ duas vezes mais elevada que a floresta baixa no horizonte Al do solo, devida, em parte, à maior deposição de serapilheira e concentração de $\mathrm{N}$ nesse material, com teores médios nas fol has de $11,6 \mathrm{~g} \mathrm{~kg}^{-1}$, na floresta al ta, e de $7,3 \mathrm{~g} \mathrm{~kg}^{-1}$ na floresta baixa (Britez, 1994).

A relação C/N (Quadro4) apresentou val ores mais el evados nos horizontes A1, Bh e Bhs, nos dois perfis da floresta baixa, atingindo o val or máximo em 12,7. A floresta alta apresentou relações $\mathrm{C} / \mathrm{N}$ bem menores com oval or mais el evado no horizonteA $1(5,5)$, devido aos teores de $\mathrm{N}$ mais elevados eà pouca lixiviação do $C$ para o horizonteB. Os baixos valores da relação no horizonte E são devidos à lixiviação da matéria orgânica, restando muito pouco $\mathrm{C}$ eN. N as duas áreas e, principalmente, na floresta alta, os valores foram bastante baixos, se comparados aos de outros trabalhos relacionados com solos podzóis. Vieira (1988), em solo podzol hidromórfico, com A moderado, obteve valores de 18, 19, 8 e 29 nos horizontes A11, A12, E e Bs, respectivamente, constatando o mesmo comportamento dos val ores da relação $\mathrm{C} / \mathrm{N}$ em termos de variação em relação à profundidade do perfil. Nos podzóis comA moderado, levantados pel o Radambrasil, em diversos locais da Amazônia, a relação $\mathrm{C} / \mathrm{N}$ apresentou valores entre 1 e 36, sendo os mais elevados nos horizontes Bh e Bs e os mais baixos no horizonte E. 
Quadro 4. Teores totais dos elementos nos solos

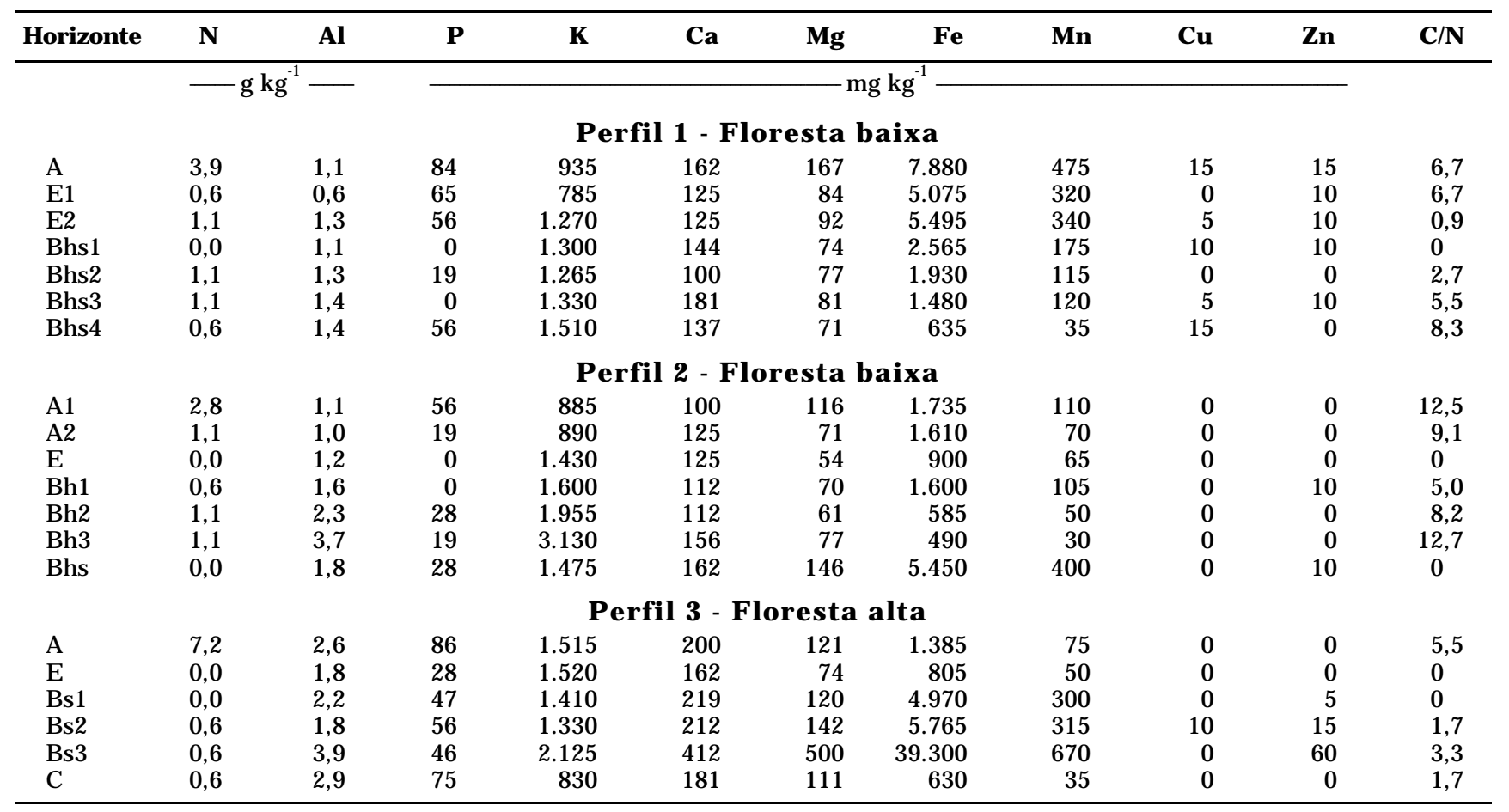

Quadro 5. Quantidades totais dos elementos minerais nos solos

\begin{tabular}{|c|c|c|c|c|c|c|c|c|c|c|c|c|}
\hline $\begin{array}{l}\text { Horizonte } \\
\text { (Espessura) }\end{array}$ & $\mathbf{N}$ & Al & $\mathbf{P}$ & $\mathbf{K}$ & $\mathbf{C a}$ & Mg & $\mathbf{F e}$ & Mn & $\mathbf{C u}$ & Zn & Total & $\begin{array}{c}\text { Total / cm } \\
\text { de solo }\end{array}$ \\
\hline $\mathrm{cm}$ & & & & & & & -1 & & & & & \\
\hline \multicolumn{13}{|c|}{ Perfil 1 - Floresta baixa } \\
\hline $\begin{array}{l}\text { A (12) } \\
\text { E1 (13) } \\
\text { E2 (49) } \\
\text { Bhs1 (24) } \\
\text { Bhs2 (22) } \\
\text { Bhs3 (18) } \\
\text { Bhs4 (23) }\end{array}$ & $\begin{array}{r}3.229 \\
889 \\
6.845 \\
0 \\
3.582 \\
2.812 \\
3.441\end{array}$ & $\begin{array}{r}911 \\
889 \\
8.090 \\
3.485 \\
4.233 \\
3.578 \\
4.379\end{array}$ & $\begin{array}{r}70 \\
96 \\
348 \\
0 \\
62 \\
0 \\
175\end{array}$ & $\begin{array}{r}774 \\
1.163 \\
7.903 \\
4.118 \\
4.119 \\
3.399 \\
4.723\end{array}$ & $\begin{array}{l}134 \\
185 \\
778 \\
456 \\
326 \\
463 \\
429\end{array}$ & $\begin{array}{l}138 \\
124 \\
573 \\
234 \\
251 \\
207 \\
222\end{array}$ & $\begin{array}{r}6.525 \\
7.521 \\
34.195 \\
8.126 \\
6.284 \\
3.783 \\
1.986\end{array}$ & $\begin{array}{r}393 \\
474 \\
2.116 \\
554 \\
374 \\
307 \\
109\end{array}$ & $\begin{array}{r}12 \\
0 \\
31 \\
32 \\
0 \\
13 \\
47\end{array}$ & $\begin{array}{r}12 \\
15 \\
62 \\
32 \\
0 \\
26 \\
0\end{array}$ & $\begin{array}{l}12.199 \\
11.358 \\
60.942 \\
17.038 \\
19.230 \\
14.587 \\
15.512\end{array}$ & $\begin{array}{r}1.017 \\
874 \\
1.244 \\
710 \\
874 \\
810 \\
674\end{array}$ \\
\hline Tot. (161) & 20.798 & 25.565 & 751 & 26.201 & 2.770 & 1.750 & 68.420 & 4.328 & 135 & 147 & 150.865 & 937 \\
\hline \multicolumn{13}{|c|}{ Perfil 2 - Floresta baixa } \\
\hline $\begin{array}{l}\text { A1 (13) } \\
\text { A2 (07) } \\
\text { E (73) } \\
\text { Bh1 (13) } \\
\text { Bh2 (19) } \\
\text { Bh3 (28) } \\
\text { Bhs (16) }\end{array}$ & $\begin{array}{r}3.349 \\
747 \\
0 \\
1.123 \\
3.072 \\
4.558 \\
0\end{array}$ & $\begin{array}{r}1.316 \\
679 \\
11.914 \\
2.995 \\
6.424 \\
15.333 \\
4.118\end{array}$ & $\begin{array}{r}67 \\
13 \\
0 \\
0 \\
78 \\
79 \\
64\end{array}$ & $\begin{array}{c}1.058 \\
604 \\
14.197 \\
2.995 \\
5.460 \\
12.971 \\
3.375\end{array}$ & $\begin{array}{r}120 \\
85 \\
1.241 \\
210 \\
313 \\
646 \\
371\end{array}$ & $\begin{array}{r}139 \\
48 \\
536 \\
131 \\
170 \\
319 \\
334\end{array}$ & $\begin{array}{r}2.075 \\
1.093 \\
8.935 \\
2.995 \\
1.634 \\
2.031 \\
12.470\end{array}$ & $\begin{array}{r}132 \\
48 \\
645 \\
197 \\
140 \\
124 \\
915\end{array}$ & $\begin{array}{l}0 \\
0 \\
0 \\
0 \\
0 \\
0 \\
0\end{array}$ & $\begin{array}{r}0 \\
0 \\
0 \\
19 \\
0 \\
0 \\
23\end{array}$ & $\begin{array}{r}8.255 \\
3.317 \\
37.468 \\
10.665 \\
17.291 \\
36.061 \\
21.670\end{array}$ & $\begin{array}{r}635 \\
474 \\
513 \\
820 \\
910 \\
1.288 \\
1.354\end{array}$ \\
\hline Tot. (169) & 12.850 & 42.779 & 301 & 40.661 & 2.985 & 1.678 & 31.233 & 2.200 & 0 & 42 & 134.727 & 797 \\
\hline \multicolumn{13}{|c|}{ Perfil 3 - Floresta alta } \\
\hline $\begin{array}{l}\text { A (18) } \\
\text { E (14) } \\
\text { Bs1(29) } \\
\text { Bs2(19) } \\
\text { Bs3(13) } \\
\text { C (25) }\end{array}$ & $\begin{array}{r}10.238 \\
0 \\
0 \\
1.653 \\
1.108 \\
2.100\end{array}$ & $\begin{array}{r}3.697 \\
3.629 \\
9.060 \\
4.959 \\
7.199 \\
10.150\end{array}$ & $\begin{array}{r}122 \\
56 \\
194 \\
154 \\
85 \\
263\end{array}$ & $\begin{array}{l}2.154 \\
3.064 \\
5.806 \\
3.664 \\
3.923 \\
2.905\end{array}$ & $\begin{array}{l}284 \\
327 \\
902 \\
584 \\
761 \\
634\end{array}$ & $\begin{array}{l}172 \\
149 \\
494 \\
391 \\
923 \\
389\end{array}$ & $\begin{array}{r}1.969 \\
1.623 \\
20.466 \\
15.883 \\
72.548 \\
2.205\end{array}$ & $\begin{array}{r}107 \\
101 \\
1.235 \\
868 \\
1.237 \\
123\end{array}$ & $\begin{array}{r}0 \\
0 \\
0 \\
28 \\
0 \\
0\end{array}$ & $\begin{array}{r}0 \\
0 \\
21 \\
41 \\
111 \\
0\end{array}$ & $\begin{array}{r}18.745 \\
8.949 \\
38.178 \\
28.225 \\
87.894 \\
18.767\end{array}$ & $\begin{array}{r}1.041 \\
639 \\
1.316 \\
1.486 \\
6.761 \\
751\end{array}$ \\
\hline Tot. (118) & 15.099 & 38.694 & 874 & 21.517 & 3.491 & 2.518 & 114.694 & 3.670 & 28 & 173 & 200.757 & 1.701 \\
\hline
\end{tabular}


Quadro 6. Quantidades de elementos trocáveis dos solos

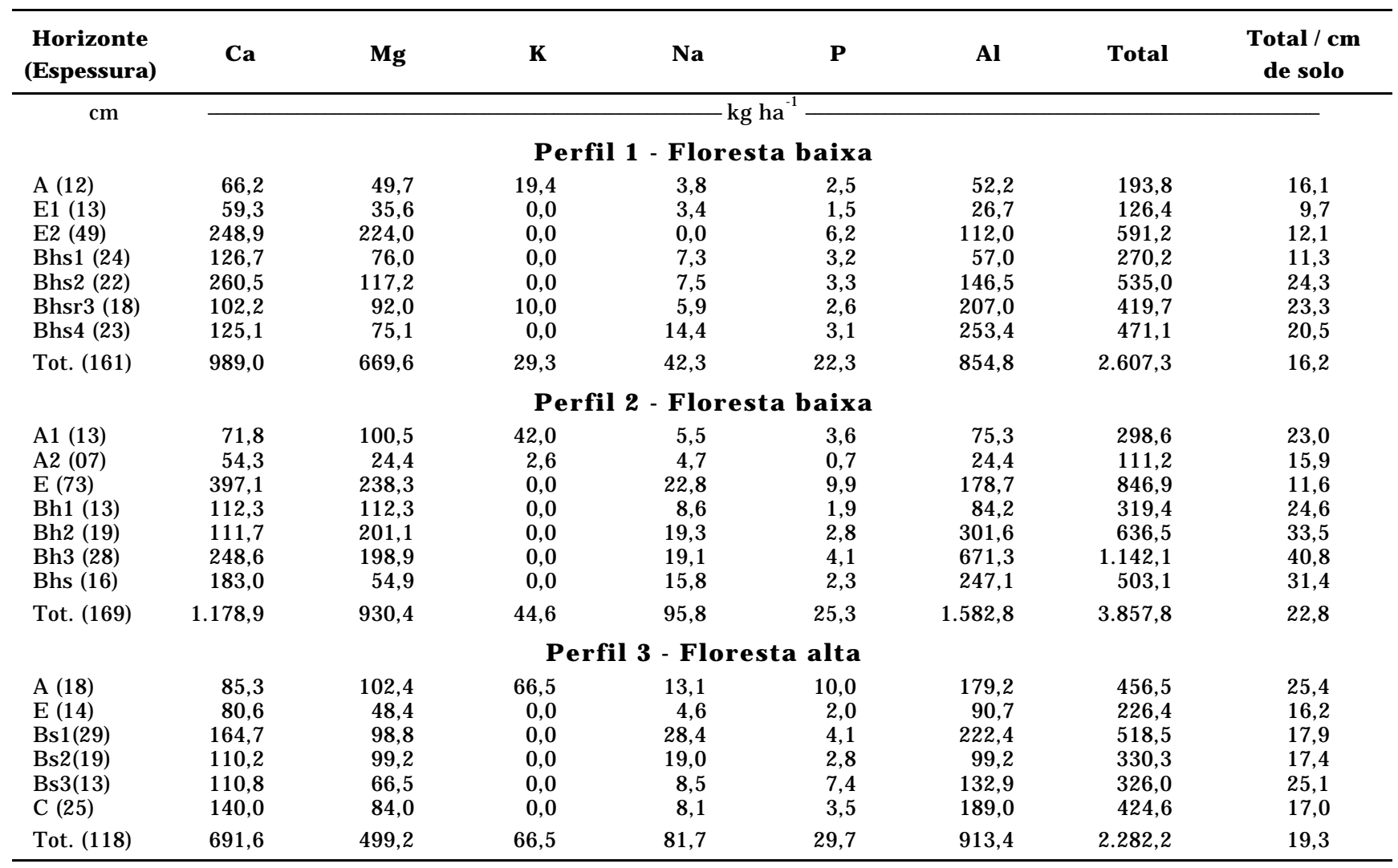

Quadro 7. Minerais ocorrentes nos sedimentos arenosos da Ilha do $\mathrm{Mel}^{(1)}$

\begin{tabular}{|c|c|}
\hline Mineral & Composição química \\
\hline Turmalina & $\begin{array}{l}\mathrm{XY}_{3} \mathrm{Al}_{6}\left(\mathrm{BO}_{3}\right)_{3}\left(\mathrm{Si}_{6} \mathrm{O}_{18}\right)(\mathrm{OH})_{4} \\
X=\mathrm{Na}, \mathrm{Ca}, \mathrm{Mg}-\mathrm{Y}=\mathrm{Al}, \mathrm{Fe}^{3}, \mathrm{Li}\end{array}$ \\
\hline Zircão & $\mathrm{ZrSiO}_{4}$ \\
\hline Pistacita & $\mathrm{Ca}_{2}(\mathrm{Al}, \mathrm{Fe}) \mathrm{Al}_{2} \mathrm{O}\left(\mathrm{SiO}_{4}\right)\left(\mathrm{Si}_{2} \mathrm{O}_{7}\right)(\mathrm{OH})$ \\
\hline Estaurolita & $\mathrm{Fe}_{2} \mathrm{Al}_{9} \mathrm{O}_{7}\left(\mathrm{SiO}_{4}\right)_{4}(\mathrm{OH})$ \\
\hline Kianita & $\mathrm{Al}_{2} \mathrm{SiO}_{5}$ \\
\hline Silimanita & $\mathrm{Al}_{2} \mathrm{SiO}_{5}$ \\
\hline Hornblenda & $\mathrm{Ca}_{2} \mathrm{Na}\left(\mathrm{Mg}, \mathrm{Fe}^{3}\right)_{4}\left(\mathrm{AlFe}^{3}, \mathrm{Ti}_{3}\right)_{3} \mathrm{Si}_{8} \mathrm{O}_{22}-(\mathrm{O}, \mathrm{OH})_{2}$ \\
\hline Magnetita(2) & $\mathrm{Fe}_{2} \mathrm{O}_{4}$ \\
\hline IImenita(2) & $\mathrm{FeO}^{-\mathrm{TiO}_{2}}$ \\
\hline
\end{tabular}

${ }^{(1)}$ Segundo Angulo et al. (1994) - Composição química segundo Dana (1965). ${ }^{(2)}$ Resultado de análises sedi mentológicas realizadas por Angulo (comunicação pessoal) de amostras do perfil do solo.

As concentrações de $\mathrm{P}$ total nos solos das áreas estudadas são bastante inferiores às da faixa de 0,2 a $1,5 \mathrm{~g} \mathrm{~kg}^{-1}$, normalmente encontrada no solo (Mengel $\&$ Kirkby, 1987), estando na faixa de 0,019 e 0,086 $\mathrm{g} \mathrm{kg}^{-1}$. No material de origem da planície arenosa, não existem minerais com fósforo, podendo haver, nesses solos, $\mathrm{P}$ proveniente de carapaças de animais marinhos (Figueiredo, 1954), além da entrada via preci pitação pluviométrica, de cerca de $0,1 \mathrm{~kg} \mathrm{ha}^{-1} \mathrm{ano}^{-1}$ (Britez, 1994). O P, da mesma maneira que o N, é, na sua maior parte de origem orgânica, o que explica suas maiores concentrações no horizonte A1 dos solos, podendo haver transporte para o horizonte B.

A maior parte do K provém de minerais primários esecundários, sendo esteelemento facilmentelixiviado. Sua fácil solubilização no podzol é comprovada pelos maioresteores nohorizonteB iluvial. OK total apresentou maiores concentrações que $\mathrm{Ca}$ e $\mathrm{Mg}$, indicando sua existência no material de origem da planícielitorânea, além da contribuição oriunda da precipitação que passa pelo dossel da floresta de cerca de $45 \mathrm{~kg} \mathrm{ha}^{-1} \mathrm{ano}^{-1}$ (Britez, 1994).

O Ca e o Mg total apresentaram teores bastante baixos, sendo provenientes, na sua maior parte, da matéria orgânica e de minerais que constituem a areia, como a turmalina e a hornblenda. Cerca de $12 \mathrm{~kg} \mathrm{ha}^{-1} \mathrm{ano}^{-1}$ de Ca e $14 \mathrm{~kg} \mathrm{ha}^{-1} \mathrm{ano}^{-1}$ de $\mathrm{Mg}$ chegam ao solo via precipitação (Britez, 1994).

O Fe apresentou altas concentrações, dada a participação desse elemento na estrutura dos mi nerais que compõem o material de origem, tais como: turmalina, estaurolita, hornblenda, magnetita e ilmenita. Uma importante característica do Fe no sol o e nas plantas é de formar complexos orgânicos ou quelatos (Mengel \& Kirkby, 1987).

A característica do podzol é a remoção do ferro do horizonte $\mathrm{E}$, sendo levado para a parte inferior do 
horizonte $\mathrm{B}$, onde se preci pita, juntamente com o Al e Mn (Vieira, 1988). I sto pode ser observado, mais claramente, no perfil 3, em que ocorre um acúmulo de $\mathrm{Fe}, \mathrm{Mn}$ e Al no horizonte Bir3, chegando o Fe a atingir a concentração de $39 \mathrm{~g} \mathrm{~kg}^{-1}$. Parte do Fe, nesse caso, pode estar em condições redutoras, visto permanecer esse horizonteconstantemente sob a água.

O Mn nos sol os da planície litorânea está presente, tanto associado à matéria orgânica quanto aos minerais constituintes da areia. N os perfis analisados, apresentou comportamento idêntico ao $\mathrm{Fe}$, em quase todos os horizontes, com uma razão Fe/Mn entre 15 e 18.

O Al total, em relação aos demais elementos, apresentou altas concentrações. Esse elemento, da mesma forma que Fe e Mn, élixiviado dos horizontes superficiais para o horizonte $B$.

O Zn e o Cu totais apresentaram baixas concentrações nos perfis analisados, pois ambos originam-se de minerais primários, podendo formar complexos quelados com a matéria orgânica (Malavolta, 1980).

\section{CONCLUSÕES}

1) Os solos das duas áreas estudadas são semel hantes em termos de fertilidade. Os val ores de soma e saturação por bases trocáveis são bastante próximos, ocorrendo, também, a presença de dois compartimentos distintos de nutrientes, um no horizonte $A 1$ e outro no horizonte B iluvial.

2) As diferenças de profundidade do horizonte $B$ dos perfis estudados podem estar relacionadas com a amplitude de oscilação do lençol freático.

3) Dois fatores são importantes para entender as características dos solos que influenciaram o desenvolvimento das duas tipol ogias florestais: a profundidade do horizonte $\mathrm{B}$ e a do lençol freático. Nos dois casos, esses estão mais próximos da superfície do sol o na floresta mais desenvolvida (floresta alta), permitindo a maior disponibilidade de nutrientes e água.

\section{LITERATURA CITADA}

ANGULO, R.J. Geologia da planície costeira do Estado do Paraná. São Paulo, Universidade de São Paulo, 1992 334p. (Tese de Doutorado)

ANGULO, R.J .; GIANNINI, P.C.F.; KOGUT, J .; PRAZERES FILHO, H.J. \& SOUZA, M.C. Variation of sedimentological parameters with deposition age across a succession of beachridges in the Holocene of Mel Island, Paraná, Brazil. In: INTERNATIONAL SEDIMENTOLOGICAL CONGRESS (1994: Recife). Anais. Recife, 1994. (No prelo).

BRITEZ, R.M. Ciclagem de nutrientes minerais em duas florestas da planície litorânea da Ilha do Mel, Paranaguá. Curitiba, Universidade Federal do Paraná, 1994. 240p. (Tese de Mestrado)
DANA, J.D. Manual of mineralogy.. New York, J ohn Wiley, 1965. 282p.

DELITTI, W.B.C. Aspectos comparativos da ciclagem de nutrientes minerais na mata ciliar, no campo cerrado e na floresta implantada de Pinus elliottii Engelm. var. elliottii (Mogiguaçu, SP). São Paulo, I nstituto de Biociências, Universidade de São Paulo, 1984. 305p. (Tese de Doutorado)

EDWARDS, P.J .\& GRUBB. Studies of mineral cycling in a montane rain forest in New Guinea. IV. Soil characteristics and the division of mineral elements between the vegetation and soil. J. Ecol., Oxford, 70:649-666, 1982.

EMBRAPA. Serviço Nacional de Levantamento de Conservação de Solos. Manual de métodos de análise de solo. Rio de J aneiro, 1979. n.p.

EMBRAPA. Levantamento de reconhecimento dos sol os do Estado do Paraná. SNLCS/SU DE SU L/I APAR, Londrina, 1984. 791p. (Boletim, 57)

EMBRAPA. Critérios para distinção de classes de solos e de fases de unidades de mapeamento - Normas em uso pelo SNLS. Rio de J aneiro, 1988. 67p. (Documentos SNLCS, 11)

FIGUEIREDO,J .C. Contribuição à geografia da I Iha do Mel (litoral do Estado do Paraná). Curitiba, Universidade Federal do Paraná. 1954. 81p. (Tese de Mestrado)

GOLLEY, F.B.; MCGINNIS, J.T.; CLEMENTS, R.G.; CHILD, G.I . \& DUEVER, M.J. . Ciclagem de minerais em um ecossistema de floresta tropical úmida. São Paulo, EDUSP, 1978. 256p.

HAY, J .D. \& LACERDA, L.D. Alterações nas características do solo após fixação de Neoregelia cruenta (R. Grah.) L.Smith (Bromeliaceae), em um ecosssistema de restinga. Ci. Cult., São Paulo, 32:863-867, 1980.

HAY, J .D.; LACERDA, L.D. \& TAN, A.L. Soil-cation increase in a tropical sand dune ecosystem due to a terrestrial bromeliad. Ecology, Durham, 62:1392-1395, 1981.

HILDEBRAND, C. Manual de análises químicas de solo e plantas. Curitiba, UFPR, 1977. 225p. (Mimeo.)

LEMOS, R.C. \& SANTOS, R.D. Manual de descrição e coleta de solos no campo. 2. ed. Campinas, Sociedade Brasileira de Ciência do Solo, 1984. 46p.

MALAVOLTA, E. Elementos de nutrição mineral das plantas. São Paulo, Ceres, 1980. 251p.

MENGEL, K.\& KIRKBY, E.A. Principles of plant nutrition. Berna, International Potash Institute, 1987. 687p.

REICHARDT, K. A água em sistemas agrícolas. São Paulo, Manole, 1987. 188p.

ROCHA, H.O.; SANTOS FILHO, A. \& REISSMANN, C.B. Condições edáficas para o desenvolvimento do palmito no litoral paranaense. In: PALMITO, ENCONTRO NACIONAL DE PESQUISADORES, 1, Curitiba, 1987. Anais. Curitiba, EMBRAPA, Centro Nacional de Pesquisa de Florestas, 1987. p.105-118.

SANTOS, V.D. Ciclagem de nutrientes minerais em mata tropical subcaducifolia dos planaltos do Paraná (Parque estadual Vila Rica do Espírito Santo - Fênix/Pr). São Carlos, Universidade de São Carlos. 1989. 385p. (Tese de Doutorado)

SANTOS FILHO, A. \& TOURINHO, L.C.N. Podzol hidromórfico da faixa litorânea paranaense. R. Set. de Ci. Agrár., Curitiba, 5:95-97, 1983. 
SILVA, S.M. Composição florística e fitossociologia de um trecho de floresta de restinga na ilha do Mel, município de Paranaguá, PR. Campinas, Universidade Estadual de Campinas. 1990. 146p. (Tese de Mestrado)

SUGUIO, K. \& MARTIN, L. Geormofologia das restingas. In: SIMPÓSIO SOBRE ECOSSISTEMAS DA COSTA SUL E SUDESTE BRASILEIRA: SÍNTESE DOS CONHECIMENTOS, 2, Águas de Lindóia, 1990. Anais. São Paulo, ACIESP, 1990, p.185-206.
TANNER, E.V.J. Four montane rain forests of J amaica: quantitative characterization of floristics, the soils and the foliar mineral levels, and a discussion of the interrelations. J. Ecol., Oxford, 65:883-918, 1977.

VETTORI, L. \& PIERANTONI, H. Análise granulométrica, novo método para determinação da fração argila. Equipe de pedologia e fertilidade do solo, Rio de J aneiro, 1968. 8p. (Boletim técnico 3)

VIEIRA, L.S. Manual da ciência do solo: com ênfase aos solos tropicais. 2. ed. São Paulo, Ceres, 1988. 464p. 